\title{
Multimedia Aspects in Online Learning Video Content
}

\author{
Andreas Rio Adriyanto ${ }^{*}$, Imam Santosa ${ }^{2}$, Achmad Syarief ${ }^{3}$
}

\author{
Doctoral Program in Visual Art and Design, Bandung Institute of Technology, Bandung, Indonesia \\ Faculty of Art and Design, Bandung Institute of Technology, Bandung, Indonesia \\ *Corresponding Author, Email: rioadriyanto@gmail.com
}

\begin{abstract}
In the Industrial Revolution 4.0 era, there was a paradigm shift of thought. The shift is from the audience to the user, from mono media to multimedia, from periodically to real time, from one direction to interactivity, from linear to hypertext, and from data to knowledge. Higher education in art and design will also be affected by this paradigm of thinking. There are still a lot of online learning materials that use face-to-face classroom material to be applied online. The research will be carried out by applying experiments to two groups of students with a focus on video learning content. One group of students will be used as a control group and another group to be an experimental group. The control group uses standard features that are commonly used in learning videos. The experimental group uses features that apply multimedia principles. The effectiveness of learning from the two groups will be measured by retention tests and transfer tests. This publication is ongoing research. Further discussion, both in the methodology and the experimental features is expected to trigger. The results of this study are expected to be used as a reference for designing online learning materials. Keywords: online learning, learning video, multimedia principle

\section{INTRODUCTION}

The progression of information technology that has changed human civilization has an influence on the social culture of the world community. Some observations of changes in civilization have been predicted in the past few decades. Toffler [1] has predicted the phenomenon of globalization that occurs in the world. He divided the transformation of human civilization into three waves; the First Wave is the settled agricultural society, and the Second Wave is the Industrial Age Society. The Third Wave is the post-industrial society that is now happening begins with the information technology revolution which is called the information age. The role of the media and its influence on society was stated by McLuhan [2]. He saw the role of the media that made all parts of the world become a global village through instant information available wherever and whenever needed. The same thing was observed by Friedman [3] who looked at the tendency of the world to be a flat world when everyone in the world was easily connected to one another. Schwab [4] revealed this phenomenon and called it the era of the Industrial Revolution 4.0. The fourth stage of the Industrial Revolution was marked by the development of digital information technology which expanded in every aspect of society.

The study of the change of global communication paradigm revealed by McLuhan, there are three stages of communication that start from an oral culture, written culture and visual culture. According to Orihuela [5], there is currently a paradigm shift in communication from visual culture to a hyper culture which is a combination of oral, written and visual culture. The first paradigm is a shift from the audience to the user. Second is a shift from media to content. Content specialization is

regarding digitalization is that text, audio, video, graphic, photographs, and animation media can be arranged simultaneously and interact in one medium. Multimedia is the internet media. The fourth paradigm is a shift from periodization to real time. The availability of content on the internet media is demanded in real time. The fifth is a shift from scarcity to abundance. Sixth is a shift from mediation by the editor to the media without mediation. Before being disseminated to the public there is a process to verify the incoming information, in the digital era that role disappears. The seventh paradigm is a shift from distribution to access. Access in the digital era means active searching in contrast to passive acceptance in the traditional era. Eighth is a shift from one direction to interactivity. In the ninth paradigm, there was a shift from linear to hypertext communication. In digital media, the narrator can divide into small fragments through multiple paths that contain links. And the tenth paradigm is a shift from data to knowledge. The main activity in digital media is analyzing data and transforming it into knowledge. The strategic mission of the media is information about information.

The progression of digital information technology has created a digital network society and has an impact on all aspects of human life. The higher education sector is also affected by the development of digital information technology. These revolutions change the way that knowledge is developed, obtained and distributed. The distance education method bridges the separation between lecturers and students through digital information technology media with minimal face-toface meetings. Distance education is offered across space and time, so students get flexibility in different times and places and use a variety of learning resources.
\end{abstract} becoming an important thing in the digital age. The third is a shift from mono media to multimedia. One strong issue 
Currently, many universities in Indonesia have implemented online lectures. The 2019 clustering of Indonesia's best higher education based on the Ministry of Research, Technology and Higher Education of the Republic of Indonesia's assessment [6] shows that the list of best higher education has implemented online learning. The state and private universities include Bandung Institute of Technology (kuliah.itb.ac.id), Gadjah Mada University (elisa.ugm.ac.id), Bogor Institute of Agricultural (lms.ipb.ac.id), Sepuluh Nopember Institute of Technology (share.its.ac.id) and University of Indonesia (ocw.ui.ac.id), Telkom (elearning.telkomuniversity.ac.id), Indonesian Islamic University (klasiber.uii.ac.id), Bina Nusantara University (onlinelearning.binus.ac.id), Parahyangan Catholic University (ide.unpar.ac.id), Atma Jaya University Yogyakarta (kuliah.uajy.ac.id) and Surabaya University (uls.ubaya.ac.id).

The online learning material is managed in a Learning Management System (LMS). The main content in LMS is teaching material which is generally in the form of presentation slide documents, lecture material and multimedia content in the form of learning videos, animation multimedia, and interactive multimedia. Generally, teaching material in online learning at universities in Indonesia uses presentation slide content and learning videos. This research will focus on learning video material. Learning videos are generally widely used in a number of online learning institutions in Indonesian universities. However, most of the online learning materials are still moved to the face-to-face model in the traditional classroom. Learning video material using the face-to-face teaching approach and give the position to students as passive spectators that watching video learning. There are institutions that prepare the material by recording videos, but there are also materials that are recorded directly from the real class or outside the class. The video is combined with the teaching material display. This condition can be seen in Figure 1 for the content of Bandung Institute of Technology online learning materials that move the condition of classrooms to be presented as part of online material. Another type of display by displaying video learning by recording in the lecture's office room and combined with visualization of teaching materials.

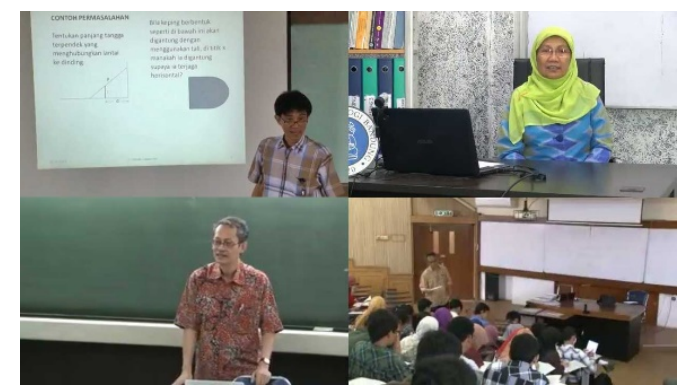

Fig. 1. Learning video from ITB online learning

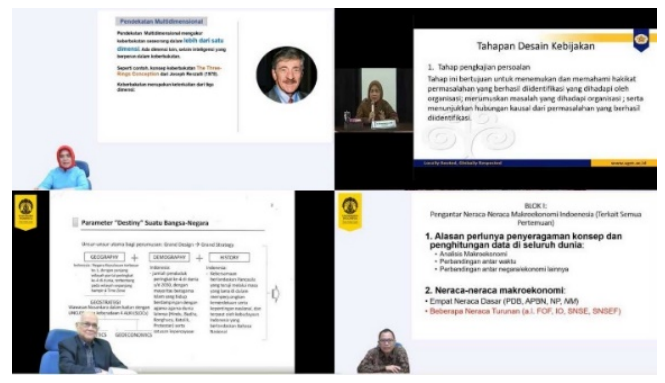

Fig. 2. Learning video from UI and UGM online learning

In addition, there are learning videos that feature instructors and teaching material content on one screen. The screen is dominated by the presentation view of learning material, and the lecturer's display becomes a small part of the screen and provides the topic of the material. Examples of these videos can be seen in Figure 2 which is a learning video from the University of Indonesia and Gadjah Mada University. The experience of students in the classroom who can directly interact with teachers and their peers is different from the experience of students in dealing with the display on a computer screen. The current generation of students is a digital generation who are in the hyper culture. They are not people who are passive receiving information, but they are people who are actively seeking information and interacting digitally. The shift from mono media to multimedia that displays a combination of text, audio, video, graphics, photographs, and animation is one of the considerations in designing instructional videos. Understanding how the principles of multimedia are applied to the learning video and user experience of the multimedia module becomes an important thing to analyze.

\section{LITERATURE REVIEW}

Outcome-Based Education (OBE) is a student-centered philosophy that is empirically focused to assess student performance in an outcome. OBE means managing and focusing on everything in the education system for students to be able to achieve certain abilities at the end of their learning experience. In relation to determining learning outcomes, one of the most widely used concepts is Bloom's taxonomy [7]. There are three domains in this learning activity: cognitive domain, affective domain, and psychomotor domain. After being revised by Anderson, et al. [8], Bloom's cognitive domain was changed from the use of nouns to verbs. The cognitive domain has levels in the categories of remembering, understanding, applying, analyzing, evaluating and creating. These levels can be divided into levels of thinking order. At the lower-order thinking level is the achievement of remembering. At the middle order thinking levels is the achievement of understanding and applying. At the higherorder thinking levels is the achievement of analyzing, evaluating and creating. The design of learning materials needs to pay attention to the learning outcomes to be achieved by students in each material.

Video is a component of multimedia and video is often used as online learning material. According to Mayer [9], decisions in designing multimedia-based learning can be seen from three views of multimedia learning, multimedia learning as response strengthening, multimedia learning as information acquisition, 
and multimedia learning as knowledge construction. As response strengthening, the scope of multimedia aims as a training system. Content from multimedia is associative. Students play a passive role as recipients of the material whose purpose is to produce an understanding of the concept of right or wrong, the teacher functions as a provider of right and wrong decisions on student responses. The purpose of this type of material content serves as an amplifier. As information acquisition, the scope of multimedia functions as a delivery system. Students play a passive role as recipients of information, teachers function as providers of information. Material is given to add information to student memory. As a knowledge construction, the scope of multimedia functions as a cognitive guidance system. The content of this multimedia is in the form of knowledge material. Students act as active logic makers, instructors function as cognitive guides. The material provided builds a mental structure of learning. This view of knowledge construction is consistent with research related to how a person learns and understands the material.

Knowledge construction is based on three assumptions of cognitive learning science. First, the assumption of two channels that include a human information processing system that consists of two channels, visual and verbal. Second, the assumption of capacity limitations which states that human memory is limited in the amount of information processed at one time. And third, the assumption of active processing which states that humans process information by building a learning mentality that includes the creation of knowledge structures that is processing, comparing, generalizing, registering, and classifying.

Furthermore, from Mayer's research, 12 multimedia principles were found in the content of multimedia-based learning materials. The first five principles aim to reduce extraneous processing are:

a. Coherence: students will learn better if extraneous materials or non-related materials are excluded from the main learning material.

b. Signaling: students will learn better if the essential things of the material (word or graphic) are given a particular highlight.

c. Redundancy: students will learn better with pictures and narrative material compared to picture, narration with additional text.

d. Spatial contiguity: students will learn better when connecting words and images that are displayed close together rather than far apart.

e. Temporal contiguity: students will learn better if words and images are displayed simultaneously rather than alternately.

The next three principles aim to manage essential processing are:

a. Segmenting: students will learn better if the material can be controlled by students rather than linearly.

b. Pre-training: students will learn better when they understand the characteristics of the main concepts.

c. Modality: students will learn better by picture material and spoken words compared to picture material and printed words.

The next four principles aim to foster generative processing are

a. Multimedia: students will learn better from material that contains a combination of text and images than text alone. b. Personalization: students will learn better when words are spoken in an informal conversation style rather than formally.

c. Voice: students will learn better with spoken words given through human voices compared to the sound of machines.

d. Image: students will not learn better with multimedia material when the narrator's figure appears on the screen.

Empirical studies conducted by Guo, Kim and Rubin [10] regarding student engagement with learning video material. This research uses data from 6.9 million learning video watching sessions on the edX Massive Open Online Courses (MOOC) platform. Measurements were made by looking at how long students were able to see each video learning. The findings of this study are that videos that are more engaging on users are shorter videos duration, the appearance of instructors appearing in a close-up medium combined with slide presentations, instructors who provide teaching materials enthusiastically and speak fast enough, display a more personal video atmosphere and visualization that write topics directly on the video screen display. Videos with recording models in the classroom do not engage with the user.

Brame [11] conducted a literature study on effective learning videos. The research suggests considering three elements for the design of learning videos and their implementation. These elements are the cognitive load, student involvement and promote active learning. The study provides recommendations on learning videos. To reduce the cognitive load, the principle of signaling associated with highlighting important information is recommended. Then, segmenting information into smaller pieces of information, removing information that does not contribute to learning goals. Finally, carrying out the process of using audio and visual channels to convey information new. To increase student engagement, it is recommended designing videos that are of short duration, using conversational language. Then, speaking enthusiastically and relatively quickly, to provide visual elements related to the student understanding. To improve active learning, this research suggested that several recommendations such as using guided questions and using interactive features that students can control. Then, making videos as part of the remaining assignments and integrating questions in the videos.

Empirical studies conducted by Moussiades, Kazanidis and Iliopoulou [12] relating to the design of learning video making frameworks. This study provides five stages of the process in designing Methodology for educational Video Development (MVD). The stage is determining general learning objectives, determining specific learning goals, video construction, evaluation, and reformation. In the video construction stage, design guidelines are using a short video duration, using a conversation style, paying attention to aesthetic factors. Then, controlling the level of conversation, defining the target audience. Designing the video display without a lot of text, using conversation narration, providing a simple picture and neat. Finally, synchronize audio and visual messages, combine visual diversity, and control the speed of the video. Using the signaling principle, provide preliminary notes relating to content, manage video in certain sections, and use subtitles for convenience for foreign students or special needs. This study uses an experiment that compares videos using the MVD process with videos produced by Brame's recommendations 
for effective learning videos. Brame's recommendations do not pay attention to instructional design elements in the design of learning videos as in the MVD process. The findings of this study are instructional videos that use the MVD process to get a higher mean than the video recommendations.

\section{Method}

The subject to be studied is lecture materials in art and design that dominant in the cognitive domain. The objective of this research is to find the possibility of developing higher education lectures in arts and design courses to be transformed into online lectures. The courses that will be tested are the basic level theory courses that are included in the lower order thinking level in the achievement of remembering (Figure 3). Phenomenology studies will be carried out before the experiment is applied. This study is related to the experience of students in using online learning material. In-depth interviews were conducted to obtain input related to the student's experience, and the results will be analyzed to be one of the features in the experiment. The result of the interview about user experience is combined with features related to multimedia principles which will then be experimented on.

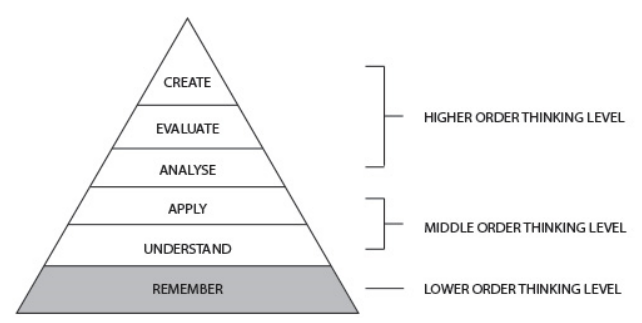

Fig. 3. Order thinking level of cognitive domain

Experiments will be conducted by taking lecture samples at two lecture meetings. The reason is that students have the basic knowledge of the previous material. Online lecture material content that will be tested is learning video content. The experiment will compare two selected groups of students with a minimum number of 30 people. One group became the control group while the other group became the experimental group. The groups will take part in two online lecture sessions with learning and evaluation video materials that are put into a Learning Management System (LMS) that has been prepared.

An evaluation will be conducted to see the learning effectiveness of each experimental group. The objective of this evaluation is to measure learning outcomes at the remembering level. Retention tests are used to measure the ability to remember important parts of the material that have delivered. The type of test used is multiple choices and fill-inthe-blank questions. The evaluation results will be obtained the group average value (mean) and the standard deviation. Standard deviation values aim to see the distribution of data and proximity to the average value (Figure 4 ).

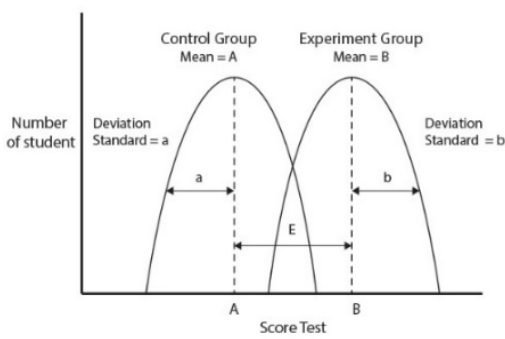

Fig. 4. Effect Size of Experiment and Control group

High average scores and low standard deviations indicate that learning materials have been effective. The difference between the experimental and control groups will be measured by the Effect Size. The process is the average value of the experimental group reduced by the average value of the control group. The results of these values are divided by the combined values of the standard deviations of the two groups. This value is the Effect Size as in:

$$
\text { Effect Size }(E)=\frac{\text { Mean } B-\text { Mean } A}{\text { Combined Deviation Standard }(a, b)}
$$

The situation shows no significant effect is indicated by effect size values below 0.2 . Moderate if the effect size is 0.5 . While the effect size value above 0.8 indicates the application of features in the experimental group has a greater influence than the control group [13]. Further observations and interviews after the experiment will be conducted to understand the user experience of the learning video has been tested.

\section{DisCUSSION}

The features developed for the experiments are developed from the input of user experience online learning, multimedia learning theories, and previous research. Learning video content will be examined the effectiveness of the learning video material content features that consider the following aspects:

1. The aspects of coherence 1: will students learn better if video material uses background noise elements compared to the material without sound elements?

2. The aspect of coherence 2: will students learn better if the video material uses a plain-colored background compared to the material with an interior/exterior background of a place?

3. The aspect of personalization: will students learn better if the video material is delivered in an informal conversation style compared to formal speech?

4. The aspect of interactivity: will students learn better if the video material is combined with student interaction of activities related to understanding the material compared to using linear video material from beginning to the end?

5. Temporal quantity aspects: will students learn better if the quantity of instructors displays time in video material is less than the appearance of instructors who appear more dominant in video material?

6. Aspects of graphic complexity: will students learn better if the elements of image media in the video are complex and detailed compared to elements of image media that are simple? 
The application of these features in experiments can be seen in Table I and Table II. In Table I, the control group using the neutral display as commonly used in online learning videos. The explanation of teaching material appears next to the instructor and in certain parts is made to fill the screen for clarity. At this first session, an experiment was conducted to see the influence of aspects of coherence and personalization. Each experimental group 1, 2, 3, will be compared with the control group.

\section{TABLE I. EXPERIMENTAL VIDEO CONTENT IN} COGNITIVE DOMAIN

\begin{tabular}{|c|c|}
\hline Group type & Use of features \\
\hline Control group & $\begin{array}{l}\text { Video learning material with the } \\
\text { appearance of the lecturer as a } \\
\text { presenter of material. The } \\
\text { conversation is using a formal } \\
\text { style. Plain color for the } \\
\text { background. No background } \\
\text { sound. Content of image and text } \\
\text { material appears next to the } \\
\text { lecturer and will be made to } \\
\text { fullscreen for certain subjects. }\end{array}$ \\
\hline $\begin{array}{l}\text { Experimental group } \\
1\end{array}$ & $\begin{array}{l}\text { Video learning material with the } \\
\text { appearance of the lecturer as a } \\
\text { presenter of material. The } \\
\text { conversation is using a formal } \\
\text { style. Plain color for the } \\
\text { background. The background } \\
\text { sound using classical piano } \\
\text { music. Content of image and text } \\
\text { material appears next to the } \\
\text { lecturer and will be made to } \\
\text { fullscreen for certain subjects. }\end{array}$ \\
\hline $\begin{array}{l}\text { Experimental group } \\
2\end{array}$ & $\begin{array}{l}\text { Video learning material with the } \\
\text { appearance of the lecturer as a } \\
\text { presenter of material. The } \\
\text { conversation is using a formal } \\
\text { style. The background is using the } \\
\text { interior room that appears } \\
\text { alternately. No background sound. } \\
\text { Content of image and text material } \\
\text { appears next to the lecturer and will } \\
\text { be made to fullscreen for certain } \\
\text { subjects. }\end{array}$ \\
\hline $\begin{array}{l}\text { Experimental group } \\
3\end{array}$ & $\begin{array}{l}\text { Video learning material with the } \\
\text { appearance of the lecturer as a } \\
\text { presenter of material. The } \\
\text { conversation is using an informal } \\
\text { conversation. Plain color for the } \\
\text { background. No background } \\
\text { sound. Content of image and text } \\
\text { material appears next to the } \\
\text { lecturer and will be made to } \\
\text { fullscreen for certain subjects. }\end{array}$ \\
\hline
\end{tabular}

Illustration of the control group and the experimental group in first session video learning as in Figure 5:

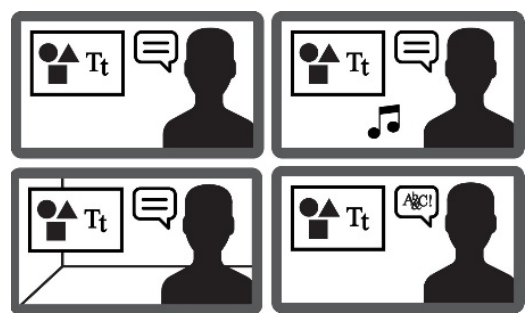

Fig. 5. Illustration of the control and experimental group - first session

In Table II, the second session experiment was conducted to see the effect of interactivity, temporal quantity, and graphic complexity. The control group using the neutral display as commonly used in online learning videos with a composition of instructor display and balanced teaching material display. This is to facilitate the distinction in the temporal aspects. Each experimental group 1,2,3, will be compared with the control group.

TABLE II. EXPERIMENTAL VIDEO CONTENT IN COGNITIVE DOMAIN

\begin{tabular}{|l|l|}
\hline Group type & Use of features \\
\hline Control group & $\begin{array}{l}\text { Video learning material with the } \\
\text { appearance of the lecturer as a } \\
\text { presenter of material. The } \\
\text { conversation is using a formal } \\
\text { style. Plain color for the } \\
\text { background. No background } \\
\text { sound. Content of image and text } \\
\text { material appears next to the } \\
\text { lecturer and will be made to } \\
\text { fullscreen for certain subjects. } \\
\text { The visual duration between } \\
\text { lecturer and the appearance of } \\
\text { lecture material (image and text) } \\
\text { is balanced. }\end{array}$ \\
\hline $\begin{array}{l}\text { Experimental } \\
\text { group 1 }\end{array}$ & $\begin{array}{l}\text { Video learning material with the } \\
\text { appearance of the lecturer as a } \\
\text { presenter of material. The } \\
\text { conversation is using a formal } \\
\text { style. Plain color for the } \\
\text { background. No background } \\
\text { sound. Content of image and text } \\
\text { material appears next to the } \\
\text { lecturer and will be made to } \\
\text { fullscreen for certain subjects. } \\
\text { The visual duration between } \\
\text { lecturer and the appearance of } \\
\text { lecture material (image and text) } \\
\text { is balanced. The pop quiz } \\
\text { appears for several segments } \\
\text { that contain questions to help } \\
\text { students understand the material } \\
\text { presented. }\end{array}$ \\
\hline Experimental \\
group 2
\end{tabular}




\begin{tabular}{|l|l|}
\hline & $\begin{array}{l}\text { presenter of material. The } \\
\text { conversation is using a formal } \\
\text { style. Plain color for the } \\
\text { background. No background } \\
\text { sound. Content of image and text } \\
\text { material appears next to the } \\
\text { lecturer and will be made to } \\
\text { fullscreen for certain subjects. } \\
\text { The Visual duration of the } \\
\text { lecturer is less than the } \\
\text { appearance of lecture material } \\
\text { (image and text). }\end{array}$ \\
\hline $\begin{array}{l}\text { Experimental } \\
\text { group 3 }\end{array}$ & $\begin{array}{l}\text { Video learning material with the } \\
\text { appearance of the lecturer as a } \\
\text { presenter of material. The } \\
\text { conversation is using a formal } \\
\text { style. Plain color for the } \\
\text { background. No background } \\
\text { sound. Content of image and text } \\
\text { material appear next to the } \\
\text { lecturer and will be made to } \\
\text { fullscreen for certain subjects. } \\
\text { The visual duration between } \\
\text { lecturer and the appearance of } \\
\text { lecture material (image and text) } \\
\text { is balanced. The appearance of } \\
\text { lecture material (image and text) } \\
\text { is made simpler and less } \\
\text { complex. }\end{array}$ \\
\hline
\end{tabular}

Illustration of the control group and the experimental group in second session video learning as in Figure 6:

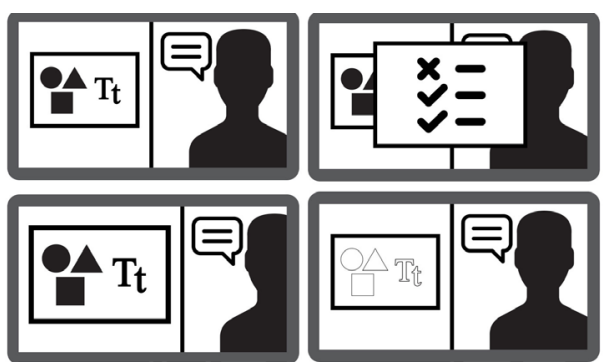

Fig. 6. Illustration of the control and experimental groupsecond session

Evaluation is carried out using a retention test to measure the level of material reminder as shown in Table III.

TABLE III. EVALUATION OF COGNITIVE DOMAIN LEARNING

\begin{tabular}{|l|l|l|}
\hline $\begin{array}{l}\text { Evaluation } \\
\text { type }\end{array}$ & Description & $\begin{array}{l}\text { Type of } \\
\text { problem }\end{array}$ \\
\hline Retention test & $\begin{array}{l}\text { Measure the ability to } \\
\text { remember important } \\
\text { parts of learning } \\
\text { material that have been } \\
\text { delivered }\end{array}$ & $\begin{array}{l}\text { choice } \\
\text { questions and }\end{array}$ \\
\hline
\end{tabular}

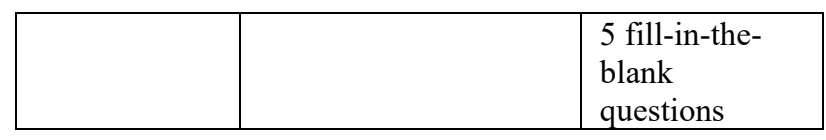

The objective of this publication is to get input and discussions on the effectiveness of online learning videos especially for lecture material from the arts and design fields that are dominant in the cognitive domain at the lower order thinking level. Further discussion regarding methodology, application of theory, development of video features, and types of evaluations that can make this research feasible to be developed is very much expected.

\section{CONClusion}

Learning videos as a component in online learning materials need to be planned well. Aspects of multimedia principles and user experience in consideration in improving students' engagement to the learning material.

\section{REFERENCES}

[1] Toffler, Alvin, and Toffler Alvin. The third wave. Vol. 484. New York: Bantam books, 1980.

[2] McLuhan, Marshall, and MARSHALL AUTOR MCLUHAN. Understanding media: The extensions of man. MIT press, 1994.

[3] Friedman, Thomas L. "The World is Flat (Farrar, Straus, and Giroux)." The New York Times (2005).

[4] Klaus, Schwab. "The fourth industrial revolution." World Economic Forum. 2016.

[5] Orihuela, José-Luis. "eCommunication: the 10 paradigms of media in the digital age." Towards new media paradigms. Content, producers, organisations and audiences. Pamplona: Ediciones Eunate (2004): 129-135.

[6] Kemenristekdikti Republik Indonesia. "Klasterisasi Perguruan Tinggi Indonesia 2019 [Indonesian University Clusterization 2019]. " Kementerian Riset dan Teknologi / Badan Riset dan Inovasi Nasional, 16 Agustus 20019, https://www.ristekdikti.go.id/kabar/menristekdiktiumumkan-klasterisasi-perguruan-tinggi-indonesia2019-fokuskan-hasil-dari-perguruan-tinggi/, 2019

[7] Bloom, Benjamin S., et al. Taxonomy of educational objetives: the classification of educational goals: handbook I: cognitive domain. No. 373.19 C734t. New York, US: D. Mckay, 1956.

[8] Krathwohl, David R., and Lorin W. Anderson. A taxonomy for learning, teaching, and assessing: A revision of Bloom's taxonomy of educational objectives. Longman, 2009.

[9] Mayer, Richard E. " Multimedia Learning." New York: Cambridge University Press (2016).

[10] Guo, Philip J., Juho Kim, and Rob Rubin. "How video production affects student engagement: An empirical 
study of MOOC videos." Proceedings of the first ACM conference on Learning@ scale conference. ACM, 2014.

[11] Brame, C.J. "Effective Educational Videos", Center for Teaching, Vanderbilt University, 2015, https://cft.vanderbilt.edu/guides-sub-pages/effectiveeducationalvideos/.
[12] Moussiades, Lefteris, Ioannis Kazanidis, and Anthi Iliopoulou. "A framework for the development of educational video: An empirical approach." Innovations in Education and Teaching International 56.2 (2019): 217-228.

[13] Cohen, J. "Statistical power analysis for the behavorial sciences. 2nd ed." (1998). 